\title{
Sibutramine Selective Electrodes for Batch and Flow Injection Determinations in Pharmaceutical Preparations
}

\author{
S. I. M. ZAYED ${ }^{* \dagger}$ and Y. M. ISSA** \\ *Faculty of Industrial Education, Beni Suef University, Beni Suef, Egypt \\ **Chemistry Department, Faculty of Science, Cairo University, Cairo, Egypt
}

\begin{abstract}
The construction and electrochemical response characteristics of two new polyvinyl chloride (PVC) membrane sensors for the determination of sibutramine hydrochloride were described. The sensors are based on the ion association complexes of sibutramine with sodium tetraphenylborate (NaTPB) or phosphotungstic acid (PTA) using dibutyl phthalate as plasticizing solvent. The sensors display a fast, stable response over the concentration range $3.84 \times 10^{-5}-1.00 \times 10^{-2} \mathrm{M}$ sibutramine hydrochloride monohydrate (SibuCl), with cationic slopes of $57.7 \pm 0.57$ and $59.7 \pm 1.79 \mathrm{mV}$ concentration decade $^{-1}$ and detection limits of $8.91 \times 10^{-6}$ and $1.47 \times 10^{-5} \mathrm{M}$ in case of sibutramine-tetraphenylborate (Sibu-TPB) and sibutramine-phosphotungstate $\left((\mathrm{Sibu})_{3}-\mathrm{PT}\right)$, respectively. The proposed sensors have been successfully applied for the determination of sibutramine hydrochloride in Regitrim capsules in batch and flow injection (FI) conditions.
\end{abstract}

(Received May 26, 2009; Accepted July 28, 2009; Published January 10, 2010)

\section{Introduction}

Sibutramine hydrochloride monohydrate (SibuCl) chemically is (士)-1-( $p$-chlorophenyl)- $\alpha$-isobutyl- $N, N$-dimethylcyclobutanemethylamine hydrochloride monohydrate [125494-59-9] (Scheme 1). It is an orally administered agent for treatment of obesity, as an appetite suppressant; it is a centrally acting serotonin-norepinephine reuptake inhibitor structurally related to amphetamines. ${ }^{1,2}$

Limited methods of determination of this drug have been reported in the literature, including high performance liquid chromatographic (HPLC), ${ }^{3-6}$ and spectrophotometric $^{7-10}$ and derivative fluorescence spectroscopic ${ }^{11}$ methods. The development and application of ion selective-electrodes continue to be of interest in pharmaceutical analysis because these sensors offer the advantages of simple design and operation, reasonable selectivity, fast response, low cost and applicability to turbid and colored solutions. A literature survey revealed that no potentiometric sensors for sibutramine have been published yet. In the present work, two new plastic membrane sensors for sibutramine have been constructed. The sensors are based on incorporation of sibutramine-tetraphenylborate (Sibu-TPB) or

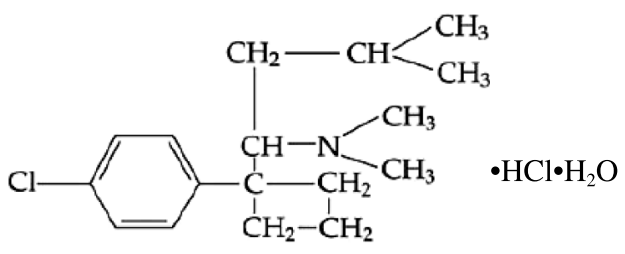

Scheme 1

\footnotetext{
$\dagger$ To whom correspondence should be addressed.
}

E-mail: simam90@hotmail.com sibutramine-phosphotungstate ((Sibu $\left.)_{3}-\mathrm{PT}\right)$ association complexes in polyvinyl chloride (PVC) plasticized with dibutyl phthalate (DBP). Application of these sensors to the determination of $\mathrm{SibuCl}$ in pharmaceutical preparations for batch and flow injection systems are being described.

\section{Experimental}

\section{Reagent and materials}

All chemicals were of analytical grade. Double distilled water was used throughout all experiments. Pure grade sibutramine hydrochloride monohydrate and the pharmaceutical preparation Regitrim capsules were provided by Medical Union Pharmaceuticals, Abu-Sultan, Ismailia, Egypt. Sodium tetraphenylborate (NaTPB), phosphotungstic acid (PTA) and dioctyl sebacate (DOS) were from Fluka; tetrahydrofuran (THF), dibutyl phthalate (DBP) and dioctyl phthalate (DOP) were from Merck. PVC of relatively high molecular weight was from Aldrich.

\section{Apparatus}

Potentiometric and $\mathrm{pH}$ measurements were carried out using a Seibold G-103 digital pH/mV meter (Vienna, Austria). A Techne circulator thermostat Model C-100 was used to control the temperature of the test solutions. A saturated calomel electrode (SCE) was used as the external reference, while a $\mathrm{Ag} / \mathrm{AgCl}$ wire was used as the internal electrode. The electrochemical system of the conventional electrode may be represented as follows: $\mathrm{Ag} / \mathrm{AgCl} /$ filling solution $\left(1 \times 10^{-1} \mathrm{M}\right.$ $\mathrm{NaCl}$ and $\left.1 \times 10^{-2} \mathrm{M} \mathrm{SibuCl}\right) /$ membrane/test solution//KCl salt bridge//saturated calomel electrode.

The flow injection setup is that previously reported. ${ }^{12}$ Figure 1 represents the schematic diagram of the flow injection system used in the measurements. 


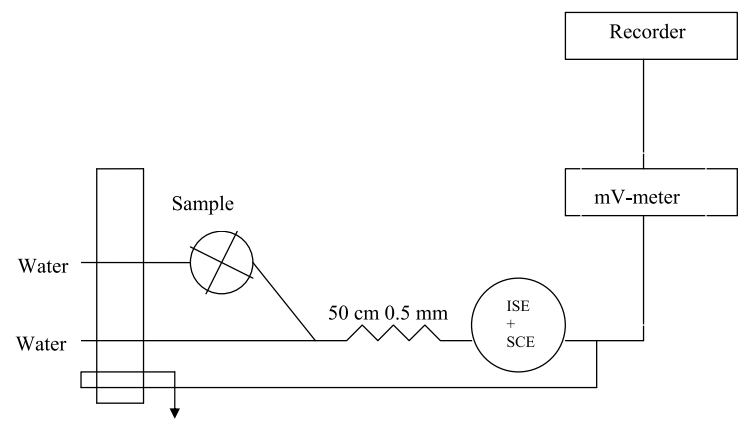

to waste

Fig. 1 Schematic diagram of the flow injection system used in the measurements.

\section{Preparation of Sibu-PVC membrane sensors}

The Sibu-TPB and (Sibu) $)_{3}-\mathrm{PT}$ ion associates were prepared by mixing $50 \mathrm{ml}$ of $1 \times 10^{-2} \mathrm{M}$ SibuCl solution with an equal amount of $1 \times 10^{-2} \mathrm{M}$ NaTPB solution or mixing $150 \mathrm{ml}$ of $1 \times$ $10^{-2} \mathrm{M}$ SibuCl solution with $50 \mathrm{ml}$ of $1 \times 10^{-2} \mathrm{M}$ PTA solution, respectively. The formed precipitates were filtered, washed thoroughly with bidistilled water until chloride free and dried at room temperature. The compositions of the ion associates were found to be 1:1 and 3:1 in cases of Sibu-TPB and (Sibu) $)_{3}$-PT ion associates, respectively, as confirmed by elemental analysis data obtained at the microanalytical research laboratory in National Research Centre, Dokki, Cairo, Egypt. The percentage values found are 79.71, 7.17 and 2.21 , and the calculated values are $79.80,7.35$ and 2.27 for $\mathrm{C}, \mathrm{H}$ and $\mathrm{N}$ in case of Sibu-TPB, while in case of $(\mathrm{Sibu})_{3}$-PT the percentage values found are 16.76 , 2.43 and 1.14, and the calculated values are 16.25, 2.17 and 1.12 for $\mathrm{C}, \mathrm{H}$ and $\mathrm{N}$, respectively. The membranes were prepared by dissolving the required amount of the ion associates, PVC and the plasticizers in about $10 \mathrm{ml}$ of THF. This cocktail was poured into a 6-cm Petri dish and left to dry in air. The thickness of the membrane was about $0.2 \mathrm{~mm}$; Diskes of the membrane were used to assemble the electrodes by the general procedure previously described. ${ }^{13}$

\section{Potentiometric determination of SibuCl}

The standard additions method ${ }^{14}$ was applied, in which small increments of standard solution $\left(3 \times 10^{-2} \mathrm{M}\right)$ of $\mathrm{SibuCl}$ were added to $50 \mathrm{ml}$ aliquot samples of various concentrations from pure drug or pharmaceutical preparation. The change in $\mathrm{mV}$ reading was recorded for each increment and used to calculate the concentration of SibuCl sample solution using the following equation:

$$
C_{\mathrm{x}}=C_{\mathrm{s}}\left(\frac{V_{\mathrm{s}}}{V_{\mathrm{x}}+V_{\mathrm{s}}}\right)\left(10^{\mathrm{n}(\Delta \mathrm{E} / \mathrm{s})}-\frac{V_{\mathrm{x}}}{V_{\mathrm{x}}+V_{\mathrm{s}}}\right)^{-1}
$$

where $C_{\mathrm{x}}$ and $V_{\mathrm{x}}$ are the concentration and the volume of the unknown, respectively, $C_{\mathrm{s}}$ and $V_{\mathrm{s}}$ the concentration and the volume of the standard SibuCl solution, respectively, $s$ the slope of the calibration graph and $\Delta E$ the change in $\mathrm{mV}$ due to the addition of the SibuCl standard solution.

\section{Determination of SibuCl in Regitrim capsules}

The contents of twenty capsules were accurately weighed and powdered in a mortar. The required amount of powder from the capsules to prepare $10^{-3} \mathrm{M} \mathrm{SibuCl}$ solution was dissolved in $30 \mathrm{ml}$ of bidistilled water and the mixture was filtered in a
Table 1 Composition of different Sibu membrane and slopes of the corresponding calibration graphs at $25 \pm 1{ }^{\circ} \mathrm{C}$ and $15 \mathrm{~min}$ of soaking in $1 \times 10^{-3} \mathrm{M} \mathrm{SibuCl}$ solution

\begin{tabular}{|c|c|c|c|c|c|}
\hline \multirow{2}{*}{ Membrane } & \multicolumn{3}{|c|}{ Composition, \% w/w } & \multirow{2}{*}{$\begin{array}{c}\text { Slope/mV } \\
\text { decade }^{-1}\end{array}$} & \multirow{2}{*}{ SD } \\
\hline & Ion associate & PVC & DBP & & \\
\hline \multirow[t]{4}{*}{ Sibu-TPB } & 3 & 48.5 & 48.5 & 53.3 & 1.51 \\
\hline & 5 & 47.5 & 47.5 & 55.5 & 0.60 \\
\hline & 7 & 46.5 & 46.5 & 57.7 & 0.57 \\
\hline & 10 & 45.0 & 45.0 & 52.5 & 2.61 \\
\hline \multirow[t]{3}{*}{$(\mathrm{Sibu})_{3}-\mathrm{PT}$} & 3 & 48.5 & 48.5 & 57.0 & 2.00 \\
\hline & 5 & 47.5 & 47.5 & 57.5 & 3.07 \\
\hline & 10 & 45.0 & 45.0 & 59.7 & 1.79 \\
\hline
\end{tabular}

100-ml measuring flask. The residue was washed three times with bidistilled water and the volume was completed to the mark by the same solvent. Fifty-milliliter solutions having concentrations $\left(5 \times 10^{-5}-1 \times 10^{-4} \mathrm{M} \mathrm{SibuCl}\right)$ were prepared by accurate dilutions. The prepared solutions were transferred into a 100-ml titration cell and subjected to potentiometric determination of SibuCl.

In FI conditions, a series of solutions of different concentrations was prepared from the capsules. The peak heights were measured and then compared with those obtained from injecting a standard solution of the same concentration prepared from pure SibuCl.

\section{Results and Discussion}

\section{Composition of the membranes}

Different membrane compositions were prepared by varying the percentages of the electroactive complex Sibu-TPB and $(\mathrm{Sibu})_{3} \mathrm{PT}$ (Table 1). The results indicated that the electrodes made by membrane with $7 \%$ Sibu-TPB or $10 \%(\mathrm{Sibu})_{3}-\mathrm{PT}$ electroactive complex exhibited the best performance characteristics (slope, $57.7 \mathrm{mV}$ concentration decade ${ }^{-1}$ at $25^{\circ} \mathrm{C}$; usable concentration range, $3.84 \times 10^{-5}-1.00 \times 10^{-2} \mathrm{M} \mathrm{SibuCl}$; detection limit, ${ }^{15} 8.91 \times 10^{-6} \mathrm{M}$; response time, $\leq 10 \mathrm{~s}$ ) for Sibu-TPB electrode. For ( $\mathrm{Sibu})_{3}$-PT electrode the characteristics are: slope, $59.7 \mathrm{mV}$ concentration decade ${ }^{-1}$ at $25^{\circ} \mathrm{C}$; usable concentration range, $3.84 \times 10^{-5}-1.00 \times 10^{-2} \mathrm{M} \quad \mathrm{SibuCl}$; detection limit, $1.47 \times 10^{-5} \mathrm{M}$; response time, $\leq 10 \mathrm{~s}$. The PVC acts as a regular support matrix for the plastic membrane ion-selective electrode, but its use requires a plasticizer which acts as a fluidizer allowing homogeneous dissolution and diffusional mobility of the electroactive complex inside the membrane. ${ }^{16}$ Three plasticizers, DBP, DOP and DOS, were examined (Table 2). The result indicated that DBP is the best of the plasticizers tested. It dissolves the ion associate complexes and adjusts both the membrane permittivity and the ion exchanger site mobility to give the highest possible sensitivity and selectivity. ${ }^{17}$ The potential response characteristics of the proposed electrodes were evaluated according to IUPAC recommendations (Table 3). ${ }^{18}$

\section{Influence of $p H$ and effect of electrolytes}

The influence of the solution $\mathrm{pH}$ on the electrode response was checked for two concentrations of SibuCl $\left(1 \times 10^{-3}\right.$ and $1 \times$ $\left.10^{-4} \mathrm{M}\right)$ by following the variation in potential with change in $\mathrm{pH}$ by addition of very small volumes of hydrochloric acid and sodium hydroxide (each $0.1-1.0 \mathrm{M}$ ). The results indicated that 
Table 2 Effect of plasticizers on Sibu responsive membrane and slopes of the corresponding calibration graphs at $25 \pm 1{ }^{\circ} \mathrm{C}$ and 15 min of soaking in $10^{-3} \mathrm{M} \mathrm{SibuCl}$

\begin{tabular}{lccc}
\hline Plasticizer & $\begin{array}{c}\text { Slope } / \mathrm{mV} \\
\text { decade }^{-1}\end{array}$ & $\begin{array}{c}\text { Usable concentration } \\
\text { range/M }\end{array}$ & $\begin{array}{c}\text { Detection } \\
\text { limit }^{15} / \mathrm{M}\end{array}$ \\
\hline Sibu-TPB & & & \\
DBP & $57.7+0.57$ & $3.84 \times 10^{-5}-1 \times 10^{-2}$ & $8.91 \times 10^{-6}$ \\
DOP & $47.5+0.65$ & $3.84 \times 10^{-5}-1 \times 10^{-2}$ & $9.27 \times 10^{-6}$ \\
DOS & $49.0+1.37$ & $3.84 \times 10^{-5}-1 \times 10^{-2}$ & $1.58 \times 10^{-5}$ \\
$(\text { Sibu })_{3}$-PT & & & \\
DBP & $59.7+1.79$ & $3.84 \times 10^{-5}-1 \times 10^{-2}$ & $1.47 \times 10^{-5}$ \\
DOP & $58.4+2.13$ & $3.84 \times 10^{-5}-1 \times 10^{-2}$ & $1.71 \times 10^{-5}$ \\
DOS & $54.7+5.24$ & $3.84 \times 10^{-5}-1 \times 10^{-2}$ & $2.51 \times 10^{-5}$ \\
\hline
\end{tabular}

Table 3 Response characteristics of Sibu sensors according to IUPAC recommendations ${ }^{18}$

\begin{tabular}{lcc}
\hline \multicolumn{1}{c}{ Parameter } & Sibu-TPB & $(\text { Sibu })_{3}-\mathrm{PT}$ \\
\hline Slope/mV decade ${ }^{-1}$ & 57.7 & 59.7 \\
Intercept/mV & 172.1 & 170.8 \\
Correlation coefficient & 0.9998 & 0.9995 \\
Linear range/M & $3.84 \times 10^{-5}-1.00 \times 10^{-2}$ & $3.84 \times 10^{-5}-1.00 \times 10^{-2}$ \\
Detection limit/M & $8.91 \times 10^{-6}$ & $1.47 \times 10^{-5}$ \\
Working $\mathrm{pH}$ range & $2.0-6.6$ & $2.0-5.6$ \\
Response time/s & $<10$ & $<10$ \\
\hline
\end{tabular}

the electrode did not response to the $\mathrm{pH}$ change in the range $2.0-6.6$ and $2.0-5.6$ for Sibu-TPB electrode and (Sibu) $)_{3}$ PT electrode, respectively (Fig. 2). The decrease in potential occurring at higher $\mathrm{pH}$ values can most probably be attributed to the formation of the free sibutramine base in the solution, leading to a decrease in the concentration of sibutraminium cation. The electrodes response was checked in bidistilled water, $0.04 \mathrm{M}$ Britton-Robinson buffer $\mathrm{pH}$ 4.0, 0.1 M acetate buffer $\mathrm{pH} 4.0$ and $0.05 \mathrm{M}$ phthalate buffer $\mathrm{pH}$ 4.2. The results reveal that the electrodes in bidistilled water provided not only a higher Nernstian slope but also a stable potential reading; in cases of buffer medium, in addition to the poor sensitivities of the electrodes, there is no stable reading for potentials. Therefore we used bidistilled water medium for further studies.

\section{Lifetime and stability of the electrodes}

Lifetimes for the electrodes were examined by performing calibration plots (pSibuCl versus $E, \mathrm{mV}$ ) as a function of soaking time. The results indicate that, in the case of Sibu-TPB electrode, the slope of the calibration graph was near $58 \mathrm{mV}$ concentration decade ${ }^{-1}$ for up to 49 days soaking in $1 \times 10^{-3} \mathrm{M}$ SibuCl solution; the slope then decreased, reaching about 54 and 49.5 concentration decade ${ }^{-1}$ after 58 and 68 days, respectively. In case of (Sibu) $)_{3}-\mathrm{PT}$ electrode, the slope of the calibration graph remained constant near 60 concentration decade $^{-1}$ for 7 days; then it decreased, reaching 55, 50 and 40 concentration decade ${ }^{-1}$ after 17, 20 and 23 days, respectively. The day-to-day precision for the slopes of the calibration plot of the proposed electrodes gave RSD $(n=4)$ of 0.63 and $1.13 \%$ for Sibu-TPB and (Sibu) $)_{3}$-PT electrode, respectively.

\section{Effect of temperature}

To study the thermal stability of the electrodes, we constructed calibration graphs at different temperatures, and we calculated, the isothermal coefficients $(\mathrm{d} E / \mathrm{d} t)$ of the selected electrodes ${ }^{19}$ to

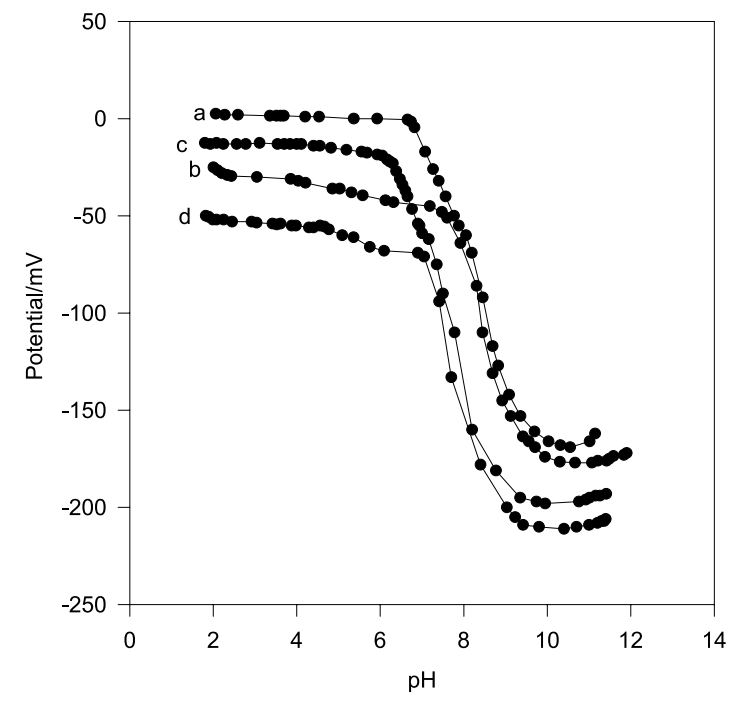

Fig. 2 Effect of the $\mathrm{pH}$ of the test solution containing $1 \times 10^{-3}$ and $1 \times 10^{-4} \mathrm{M} \mathrm{SibuCl}$ on the potential response of the Sibu electrodes: a and b, Sibu-TPB; c and d, (Sibu) $)_{3}-\mathrm{PT}$.
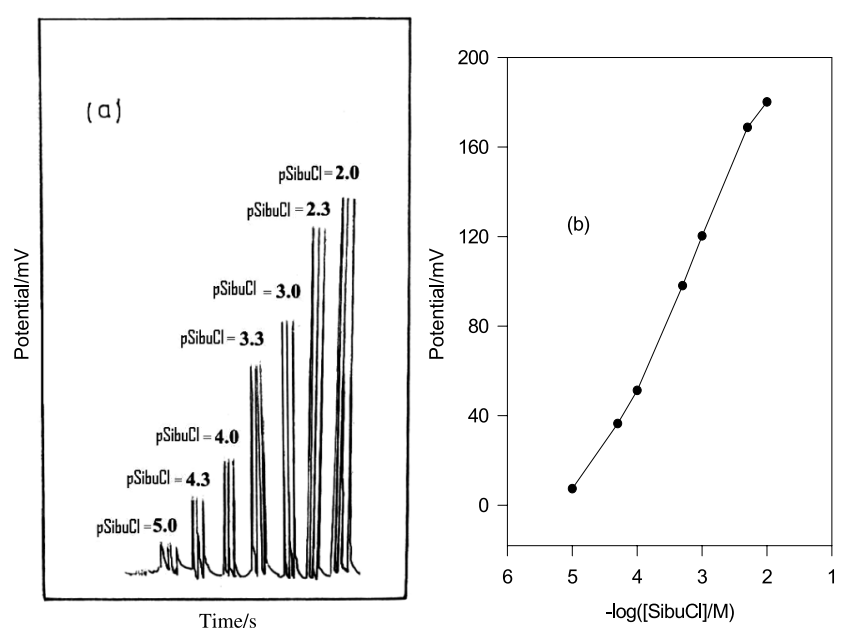

Fig. 3 Recording (a) and corresponding calibration graph (b) for Sibu-TPB electrode under FI conditions.

be -0.0024 and $-0.0021 \mathrm{~V} /{ }^{\circ} \mathrm{C}$ for $\mathrm{Sibu}-\mathrm{TPB}$ and $(\mathrm{Sibu})_{3}-\mathrm{PT}$ electrodes, respectively.

\section{FI conditions}

FI parameters were optimized in order to achieve the best signal sensitivity. The dispersion coefficients were found to be 1.15 for Sibu-TPB or (Sibu) $)_{3}$-PT electrode; this limited dispersion aids the optimum sensitivity and the fast response of the electrodes. ${ }^{20}$

Samples of different volumes $(4.7-500.0 \mu \mathrm{l})$ from the drug solution were injected at constant flow rate. The higher the sample volume, the higher the peak height and the longer the residence time of the sample at the electrode surface; such samples require a longer time to reach a steady state and greater consumption of sample. ${ }^{21}$ The optimum sample loop size was found to be 75 and $150 \mu \mathrm{l}$ for Sibu-TPB and (Sibu) $)_{3}-\mathrm{PT}$ electrodes, respectively, giving maximum peak height, less consumption of reagents, and a shorter time to reach the base line. The effect of flow rate on the electrode response was 
studied at different flow rates $(4.15-30.00 \mathrm{ml} / \mathrm{min})$, with constant injection sample loop size of 75 or $150 \mu \mathrm{l}$ in case of Sibu-TPB and (Sibu) ${ }_{3}$-PT electrodes, respectively. The residence time of the sample was inversely proportional to the flow rate. ${ }^{22}$ It was found that, as the flow rate increases, the peak becomes higher and narrower until flow rates of 17.85 and $12.50 \mathrm{ml} / \mathrm{min}$ are reached in cases of Sibu-TPB and (Sibu) $)_{3}$-PT electrode, respectively; the peaks obtained above these flow rates were nearly the same. These flow rates were used throughout this work providing the maximum peak height, a shorter time to reach the base line and less consumption of the carrier solution. Under these conditions, the performance characterstics are: slope, 64.9 and $73.5 \mathrm{mV}$ concentration decade ${ }^{-1}$, for Sibu-TPB and $(\mathrm{Sibu})_{3}$-PT electrode, respectively; usable concentration range, $\quad 5.0 \times 10^{-5}-1.0 \times 10^{-2} \mathrm{M} \mathrm{SibuCl}$; detection limit, $2.0 \times 10^{-5} \mathrm{M}$ for both electrodes. Figure 3 represents a typical recording and the calibration graph for Sibu-TPB electrode.

\section{Selectivity of the electrodes}

The influences of some inorganic cations, sugar, amino acids, vitamins and urea were investigated. The selectivity coefficients were determined by the separate solution method $(\mathrm{SSM})^{23}$ in which the Nicolsky-Eisenman equation was used:

Table 4 Selectivity coefficients $\left(-\log K_{\text {Sibu, }^{\mathrm{p}}{ }^{\mathrm{p}}}^{\mathrm{pot}}\right)$ for the Sibu electrodes in batch (SSM and MPM) and FI conditions

\begin{tabular}{lccccccc}
\hline & \multicolumn{3}{c}{ Sibu-TPB } & & \multicolumn{3}{c}{$(\text { Sibu })_{3}$-PT } \\
\cline { 2 - 5 } \cline { 6 - 8 } Interferent & SSM & MPM & FI & & SSM & MPM & FI \\
\hline $\mathrm{Na}^{+}$ & 1.802 & - & 1.75 & & 1.91 & - & 1.97 \\
$\mathrm{~K}^{+}$ & 1.970 & - & 1.68 & & 1.98 & - & 1.83 \\
$\mathrm{Ca}^{2+}$ & 3.507 & - & 3.05 & & 3.51 & - & 3.12 \\
$\mathrm{Mg}^{2+}$ & 3.451 & - & 3.00 & & 3.56 & - & 3.05 \\
$\mathrm{Fe}^{3+}$ & 3.895 & - & 3.37 & & 3.23 & - & 3.27 \\
$\mathrm{Zn}^{2+}$ & 3.163 & - & 3.07 & & 3.64 & - & 3.02 \\
$\mathrm{Co}^{2+}$ & 3.191 & - & 3.11 & & 2.87 & - & 2.93 \\
Vitamin $\mathrm{B}_{1}$ & 1.315 & - & 1.60 & & 1.59 & - & 1.35 \\
Vitamin $\mathrm{B}_{6}$ & 1.384 & - & 1.68 & & 1.67 & - & 1.77 \\
$\mathrm{Glucose}^{2+}$ & - & 2.65 & - & & - & 2.52 & - \\
Fructose & - & 2.80 & - & & - & 2.51 & - \\
Lactose & - & 2.79 & - & & - & 2.59 & - \\
Maltose & - & 2.57 & - & & - & 2.23 & - \\
Glycine & - & 2.03 & - & - & 1.35 & - \\
Alanine & - & 2.06 & - & & - & 1.61 & - \\
Urea & - & 1.68 & - & - & 1.86 & - \\
\hline
\end{tabular}

$$
\log K_{\text {Sibu, } \mathrm{J}^{2+}}^{\mathrm{pot}}=\left(E_{2}-E_{1}\right) / S+\log [\mathrm{Sibu}]-\log \left[\mathrm{J}^{\mathrm{z}+}\right]^{1 / \mathrm{z}}
$$

where $E_{1}$ and $E_{2}$ are the electrode potential in a $1 \times 10^{-3} \mathrm{M}$ SibuCl solution and interfering ions $\mathrm{J}^{\mathrm{z}}$, repectively, and $S$ is the slope of the calibration graph in $\mathrm{mV}$ concentration decade ${ }^{-1}$. In FI conditions, a series of standard solutions of $\mathrm{SibuCl}$ of concentration between $10^{-5}$ and $10^{-2} \mathrm{M}$ were prepared; their corresponding potentials were measured and used to determine the slope of the calibration graph. Solutions of $1 \times 10^{-3} \mathrm{M}$ of interfering ions were prepared; their corresponding peak heights were measured. The selectivity coefficients were calculated using the above equation. The selectivity coefficients in cases of species without charges were determined using the matched potential method (MPM). ${ }^{24}$ The potentiometric selectivity coefficient is defined in this method as the activity ratio of primary ions and interfering ions that give the same potential change under identical conditions. At first, a known activity of sibutramine ion solution is added into a reference solution which contains a fixed activity of sibutramine ion solution $\alpha_{\text {Sibu }}$, ( $\alpha_{\text {Sibu }}^{\prime}-\alpha_{\text {Sibu }}$ is the change in activity), and the corresponding potential change $(\Delta E)$ is recorded. Next, a solution of an interfering ion is added to the reference solution until the same potential change $(\Delta E)$ is recorded. The change in potential produced at the constant background of the primary ion must be the same in both cases.

$$
K_{\text {Sibu, } \mathrm{J}^{++}}^{\mathrm{Pot}}=\frac{\alpha_{\text {Sibu }}^{\prime}-\alpha_{\mathrm{Sibu}}}{\alpha_{\mathrm{J}}}
$$

where $\alpha_{\mathrm{J}}$ is the activity of the added interferent.

The selectivity coefficients values $-\log K_{\text {Sibu, } I^{z+}}^{\text {pot }}$ of the electrodes listed in Table 4 reflect a high selectivity of these electrodes towards sibutramine cation, under both batch and flow injection conditions.

\section{Analytical applications}

The usefulness of the proposed electrodes was examined by using the investigated electrodes for the potentiometric determination of $\mathrm{SibuCl}$ in pure solutions and in pharmaceutical preparation Regitrim capsules (15 mg SibuCl/capsule) in batch and FI conditions. The mean recovery and the relative standard deviation values are summarized in Table 5. The data indicate that there is no interference from the excipients used in the formulations of the capsules. As the drug is not listed in any pharmacopoeia yet, the results were compared with the UV spectrophotometric published $\operatorname{method}^{9}$ (Table 6). The results are in good agreement with those obtained from the reference

\begin{tabular}{|c|c|c|c|c|c|c|c|c|c|c|c|c|}
\hline & \multicolumn{4}{|c|}{ Pure solution } & \multicolumn{8}{|c|}{ Regitrim capsule } \\
\hline & \multicolumn{4}{|c|}{ Standard addition } & \multicolumn{4}{|c|}{ Standard addition } & \multicolumn{4}{|c|}{ FI } \\
\hline & Taken/M & Found/M & $\begin{array}{c}\text { Rec., } \\
\%\end{array}$ & $\begin{array}{c}\mathrm{RSD}, \\
\%\end{array}$ & Taken/M & Found/M & $\begin{array}{c}\text { Rec., } \\
\%\end{array}$ & $\begin{array}{c}\mathrm{RSD}, \\
\%\end{array}$ & Taken/M & Found/M & $\begin{array}{c}\text { Rec., } \\
\%\end{array}$ & $\begin{array}{c}\mathrm{RSD}, \\
\%\end{array}$ \\
\hline \multirow[t]{4}{*}{ Sibu-TPB } & $5.00 \times 10^{-5}$ & $4.95 \times 10^{-5}$ & 99.0 & 1.55 & $5.00 \times 10^{-5}$ & $4.98 \times 10^{-5}$ & 99.6 & 0.936 & $5.00 \times 10^{-5}$ & $4.94 \times 10^{-5}$ & 98.80 & 1.012 \\
\hline & $1.00 \times 10^{-4}$ & $9.68 \times 10^{-5}$ & 96.8 & 1.51 & $8.00 \times 10^{-5}$ & $7.98 \times 10^{-5}$ & 99.8 & 1.013 & $8.00 \times 10^{-5}$ & $7.97 \times 10^{-5}$ & 99.63 & 1.205 \\
\hline & $5.00 \times 10^{-4}$ & $4.89 \times 10^{-4}$ & 97.8 & 0.53 & $1.00 \times 10^{-4}$ & $9.89 \times 10^{-5}$ & 98.9 & 0.951 & $1.00 \times 10^{-4}$ & $1.004 \times 10^{-4}$ & 100.40 & 0.748 \\
\hline & $1.00 \times 10^{-3}$ & $9.66 \times 10^{-4}$ & 96.6 & 2.85 & & & & & $1.00 \times 10^{-3}$ & $1.004 \times 10^{-3}$ & 100.40 & 1.468 \\
\hline \multirow[t]{4}{*}{$(\mathrm{Sibu})_{3}-\mathrm{PT}$} & $5.00 \times 10^{-5}$ & $4.87 \times 10^{-5}$ & 97.4 & 3.31 & $5.00 \times 10^{-5}$ & $4.99 \times 10^{-5}$ & 99.8 & 0.934 & $5.00 \times 10^{-5}$ & $5.00 \times 10^{-5}$ & 100.00 & 1.582 \\
\hline & $1.00 \times 10^{-4}$ & $9.82 \times 10^{-5}$ & 98.2 & 0.87 & $8.00 \times 10^{-5}$ & $8.00 \times 10^{-5}$ & 100.0 & 1.105 & $8.00 \times 10^{-5}$ & $7.95 \times 10^{-5}$ & 99.38 & 0.809 \\
\hline & $5.00 \times 10^{-4}$ & $4.98 \times 10^{-4}$ & 99.6 & 0.69 & $1.00 \times 10^{-4}$ & $9.62 \times 10^{-5}$ & 96.2 & 1.600 & $1.00 \times 10^{-4}$ & $9.94 \times 10^{-5}$ & 99.40 & 1.394 \\
\hline & $1.00 \times 10^{-3}$ & $9.70 \times 10^{-4}$ & 97.0 & 1.53 & & & & & $1.00 \times 10^{-3}$ & $9.91 \times 10^{-4}$ & 99.10 & 1.184 \\
\hline
\end{tabular}

Table 5 Determination of SibuCl in pure form and pharmaceutical preparations by applying standard addition method and FI technique 
Table 6 Statistical comparision between results of determination of Regitrim capsules on applying the proposed and reference methods

\begin{tabular}{lcc}
\hline \multicolumn{1}{c}{ Parameter } & Sibu-TPB & $(\text { Sibu })_{3}$-PT \\
\hline Standard addition & & \\
Mean recovery, \% & 99.43 & 98.67 \\
SD, \% & 0.962 & 1.192 \\
RSD, \% & 0.967 & 1.208 \\
$F$-ratio $(9.28)^{\mathrm{a}}$ & 1.787 & 1.164 \\
$t$-test $(2.447)^{\mathrm{b}}$ & 0.996 & 1.802 \\
FI & & \\
Mean recovery, \% & 99.81 & 99.47 \\
SD, \% & 1.106 & 1.236 \\
RSD, \% & 1.108 & 1.243 \\
$F$-ratio $(9.28)^{\mathrm{a}}$ & 1.352 & 1.083 \\
$t$-test $(2.447)^{\mathrm{b}}$ & 0.531 & 0.920 \\
Reference method & & \\
Mean recovery, $\%$ & 100.27 & \\
SD, \% & 1.286 & \\
RSD, \% & 1.283 & \\
\hline
\end{tabular}

Average of four determinations for the proposed and reference methods.

a. Tabulated $F$-values at $95 \%$ confidence level.

b. Tabulated $t$-values at $95 \%$ confidence level and 6 degrees of freedom.

method. The results were statistically evaluated using $t$ - and $F$-tests ${ }^{25}$ (at 95\% confidence level). The results indicate that the calculated $t$ - and $F$-values did not exceed the theoretical values.

\section{Conclusions}

Experimental comparison of two ion associate complexes of Sibu for use as electroactive compounds using different plasticizers in potentiometric sensors revealed that, in most cases, the Sibu membrane sensor displayed good analytical performance characteristics. The proposed electrodes offer the advantage of fast response, good selectivity, long time stability, simple operation, low cost and direct application over a wide $\mathrm{pH}$ range without prior sample treatment. The proposed sensors might be useful detectors in batch and flow injection conditions for determination of Sibu in its pharmaceutical preparation.

\section{References}

1. S. C. Sweetman, Martindale, "The Complete Drug Reference", 34th ed., 2005, Pharmaceutical Press, London, 1593.
2. "New Drugs", Australian Prescriber, 2002, 25, 22.

3. J. G. Chandorkar, V. B. Kotwal, N. S. Dhande, M. P. Pachpor, and V. V. Pande, Pak. J. Pharm. Sci., 2008, 21, 121.

4. Z. Huang, S. Xiao, D. Luo, B. Chen, and S. Yao, J. Chromatogr. Sci., 2008, 46, 707.

5. A. I. Segall, E. A. Collado, A. Riccir, and M. T. Pizzorno, J. Liq. Chromatogr. Relat. Technol., 2003, 26, 977.

6. A. K. Singh, L. G. Pedro, F. P. Gomes, H. M. Yano, M. T. Auricchio, E. R. Kedor-Hackmann, and M. I. Santoro, J. AOAC Int., 2008, 91, 572

7. Z. Qin, R. Tan, L. Pu, and H. Jiang, Chin. J. Anal. Chem., 2006, 34, 403.

8. R. Valarmathi, S. K. K. Sundari, and R. Revathi, The Indian Pharmacist, 2004, 3, 71.

9. R. Valarmathi, S. K. K. Sundari, A. Puratchikody, S. George, S. S. Kumar, and K. Ruckmani, Indian J. Pharm. Sci., 2003, 65, 647.

10. D. F. Maluf, P. V. Farago, S. M. W. Barreira, C. F. Pedroso, and R. Pontarolo, Lat. Am. J. Pharm., 2007, 26, 909.

11. Z.-H. Qin, Y. Liu, R. Tan, and L.-J. Ru, Chin. J. Anal. Lab., 2006, 25, 9.

12. Y. M. Issa and S. I. M. Zayed, Talanta, 2006, 69, 481.

13. A. Craggs, G. J. Moody, and J. D. R. Thomas, J. Chem. Educ., 1974, 51, 541.

14. E. Baumann, Anal. Chim. Acta, 1986, 42, 127.

15. R. P. Buck and V. V. Cosofret, Appl. Chem., 1993, 65, 1849.

16. T. K. Malongo, B. Blankert, O. Kambu, K. Amighi, J. Nsangu, and J.-M. Kauffmann, J. Pharm. Biomed. Anal., 2006, 41,70 .

17. N. A. El-Ragehy, A. M. El-Kosasy, S. S. Abbas, and S. Z. El-Khateeb, Anal. Chim. Acta, 2000, 418, 93.

18. R. P. Buck and E. Lindner, Pure Appl. Chem., 1994, 66, 2527.

19. U. Oesch, D. Ammann, and W. Simon, Clin. Chem., 1986, $32,1448$.

20. M. Trojanowicz and W. Matuszewski, Anal. Chim. Acta, 1982, $138,71$.

21. X. Yang, D. B. Hibbert, and P. W. Alexander, Anal. Chim. Acta, 1998, 372, 387.

22. W. Frenzel and P. Bratter, Anal. Chim. Acta, 1986, 185, 187.

23. G. G. Guibault, R. A. Durst, M. S. Frant, H. Freiser, E. H. Hansen, T. S. Light, E. Pungor, G. A. Rechnitz, N. M. Rice, T. J. Roohm, W. Simon, and J. D. R. Thomas, Pure Appl. Chem., 1976, 48, 127.

24. Y. Umezawa, P. Buhlmann, K. Umezawa, K. Tohda, and S. Amemiya, Pure Appl. Chem., 2000, 72, 1851.

25. J. C. Miller and J. N. Miller, "Statistics for Analytical Chemistry", 3rd ed., 1993, Ellis Horwood, Chichester, 53. 